\title{
Comparative study between transanal endorectal pull-through and modified Duhamel's procedure in management of Hirshsprung's disease
}

\author{
Mohammed Abd El Baky Fahmy, Sameh Abd El Hay Abd El Hamid², Omar Mohammed \\ Elsamahy $^{1}$, Hanan Mahmoud Mohammed ${ }^{1}$ \\ ${ }^{1}$ Pediatric Surgery, Faculty of Medicine, Al Azhar University for Girls, ${ }^{2}$ Pediatric Surgery, Faculty of \\ Medicine, Ain Shams University
}

Corresponding author: Hanan Mahmoud Mohammed, E-Mail: Hananm1882@ gmail.com, Mobile: 01065084549

\begin{abstract}
Background- Hirschsprung's disease (HD) is a congenital disorder characterized by an absence of neuronal cell bodies in both myenteric and submucous plexuses in the intestinal wall. The aganglionosis always starts distally and is limited to the rectum and the sigmoid colon in $80-85 \%$ of the cases.HD occurs in about 1/5000 live born babies and is more common in boys than girls (4:1). Patients with HD are most often diagnosed in the neonatal period. The clinical presentation is distended abdomen, delayed passage of meconium and vomiting, older children more often present with chronic constipation, approximately $10 \%$ of patients with HD present with enterocolitis. Surgical management for HD aims at removing the aganglionic bowel and reconstructing the intestinal tract. There has been a continuous development over the years of operative techniques used for HD from multi-staged procedures (a preliminary colostomy) to one stage pull-through.Aim of the work: comparative study between transanal endorectal pull-through and modified Duhamel's procedure in management of Hirshsprung's disease. Patients and Methods: this randomized prospective study was done on 20 patients with Hirschsprung's disease during the period from January 2016 to January 2018, group A included 10 patients underwent modified Duhamel's procedure compared to group B 10 patients underwent trans-anal endorectal pull-through procedure. Results: the two techniques were nearly equivalent in the post-operative outcomes. Conclusion: currently, as there was no evidence suggesting that one technique has significant superiority over another, so it is up to surgeon's choice to select the technique that was easy and feasible in his hands, but TEPT was preferable for neonates, with no past history of enterocolitis and using modified Duhamel's if the two staplers were available is safe and with less complications
\end{abstract}

Keywords: Hirschsprung's disease, transanal endorectal pull through, modified Duhamel's procedure.

\section{INTRODUCTION}

Hirschsprung's disease (HD) is a congenital gastro-intestinal motility disorder characterized by an absence of neuronal cell bodies in both auerbach's and miessner's plexuses in the intestinal wall (1). The aganglionosis, pathognomonic for HD, always starts distally and was restricted to the rectum and the sigmoid colon in $80-85 \%$ of the cases, less frequently, the aganglionosis involves the whole colon with or without a part of the small intestine. Functionally, this results in a sustained contraction of the aganglionic segment causing obstructive symptoms ${ }^{(2)}$. HD occurs in about 1/5000 live born babies and is more common in males than females $(4: 1)^{(3)}$. The patients with HD were mostly diagnosed in the neonatal period ${ }^{(4)}$. The clinical presentation was distended abdomen, delayed passage of meconium and vomiting, older children often present with chronic constipation, and Approximately $10 \%$ of patients with HD present with enterocolitis ${ }^{(1)}$.

Contrast enema was the first diagnostic procedure and showed a transition zone between the normal (often dilated) and the narrow aganglionic bowel in about $70-90 \%$ of the cases ${ }^{(5)}$. For definite diagnosis a rectal biopsy was needed for histological evaluation 
(absence of ganglion cells and finding of hypertrophied nerve trunks) ${ }^{(6)}$. Surgical management for HD aimed at removing the aganglionic bowel and reconstructing the intestinal tract by bringing the normally innervated bowel down to the anus while, preserving normal sphincter function. Swenson and Bill were the first to describe a surgical management for $\mathrm{HD}$ by removing the aganglionic bowel with a pull-through in 1948 (7). Rehbein had also described techniques for HD management ${ }^{(8)}$. The time-honored approach to therapy was to perform a preliminary colostomy in the normally innervated bowel in the neonatal period and subsequent definitive pull-through later on (at 6 to 15 months of age). Pediatric surgeons are performing definitive pull-through procedures without a colostomy in the neonatal period ${ }^{(9)}$. However, it is still universally accepted that a preliminary colostomy may be indicated for specific children (severe enterocolitis (EC), malnutrition, perforation or massive dilatation of proximal bowel) ${ }^{(10)}$.

\section{SUBJECTS and METHODS}

This randomized prospective study was conducted in collaboration between the Pediatric Surgery Department at Al-Zahraa University Hospital, Faculty of Medicine, AlAzhar University and Pediatric Surgery Department, Faculty of Medicine, Ain Shams University Hospital. This study was approved by the Ethics Board of Al-Azhar University. All patients were collected from the Outpatient Clinic and Pediatric Surgery Department at AlZahraa University Hospital and Ain Shams University Hospital over a period from January 2016 to January 2018, with appropriate consent to participate in this study. Those subjects were categorized into 2 groups: A\&B. Group A included 10 patients operated at the Pediatric Surgery Unit, El Zahraa University Hospital, Al Azhar University where a Modified Duhamel's procedure was done, while group B included 10 patients who were subjected to transanal endo rectal pull-through at the Pediatric Surgery Unit, Ain shams University Hospital, Ain shams University.

\section{Inclusion criteria}

- Patients with proven tissue diagnosis of HD

- Patients who planned to be operated as one stage

- Patients with initial colostomy

- Patients who had recto-segmoid or long segment HD

\section{Exclusion criteria:}

- Children or neonates with total colonic aganglionosis

- Patients requiring only a sphincterotomy or myectomy

\section{Diagnosis was based on:}

- $\quad$ Detailed history and Clinical examination.

- $\quad$ Contrast enema and rectal biopsy

\section{Post-operative Follow up assessment reviewed:}

- Stooling pattern.

- Post-operative complications (fecal Continence, constipation and abdominal distention).

- Enterocolitis (EC) episodes.

- Healing of anastomosis (leakage or fistula).

- Scar complications

\section{Comparative Criteria}

- $\quad$ Age of the patient

- Operative time

- $\quad$ Blood loss

- Feasibility of dissection

- Intra operative complications

- $\quad$ Length of resected segment

- Hospital stay

- Recovery period

- $\quad$ Post-operative complications

\section{RESULTS}

There was a statistically significant difference ( $\mathrm{p}$-value $<0.05$ ) between the studied groups as regard age of patients, and length of resected segment.

Results showed no statistical significant difference ( $\mathrm{p}$-value $<0.05$ ) between the studied groups as regard intra-operative blood loss, 
recovery period, hospital stay, continence,

frequent stooling,enterocolitis and constipation.

Table 1: comparison between studied groups as regard age, operative time, length of resected segment, recovery period and hospital stay by using T-test

\begin{tabular}{|c|c|c|c|c|c|}
\hline \multicolumn{2}{|l|}{ Groups } & \multirow{2}{*}{$\begin{array}{l}\text { Group A } \\
(\mathrm{N}=10)\end{array}$} & \multirow{2}{*}{$\begin{array}{l}\text { Group B } \\
(\mathrm{N}=10)\end{array}$} & \multicolumn{2}{|c|}{ T-Test } \\
\hline & & & & $\mathrm{T}$ & p-value \\
\hline \multirow{2}{*}{ Age of patients(month) } & Mean & 37.4 & 14.6 & \multirow{2}{*}{2.7} & \multirow{2}{*}{0.002} \\
\hline & $\pm \mathrm{SD}$ & 24.9 & 8.5 & & \\
\hline \multirow{2}{*}{ Operative time(minutes) } & Mean & 145 & 141 & \multirow{2}{*}{0.4} & \multirow{2}{*}{0.7} \\
\hline & $\pm \mathrm{SD}$ & 24.9 & 22.3 & & \\
\hline \multirow{2}{*}{$\begin{array}{l}\text { length of resected segment } \\
(\mathrm{cm})\end{array}$} & Mean & 19.2 & 28.9 & \multirow{2}{*}{3.5} & \multirow{2}{*}{0.002} \\
\hline & $\pm \mathrm{SD}$ & 5.09 & 6.9 & & \\
\hline \multirow{2}{*}{ Recovery period (day) } & Mean & 20.1 & 18.3 & \multirow{2}{*}{0.9} & \multirow{2}{*}{0.4} \\
\hline & $\pm \mathrm{SD}$ & 5.3 & 3.7 & & \\
\hline \multirow{2}{*}{ Hospital stay (day) } & Mean & 13.1 & 10.9 & \multirow{2}{*}{1.2} & \multirow{2}{*}{0.2} \\
\hline & $\pm \mathrm{SD}$ & 3.7 & 3.9 & & \\
\hline
\end{tabular}

Table 2: comparison between studied groups as regard: blood loss, continence, frequent stooling, enterocolitis, and constipation

\begin{tabular}{|c|c|c|c|c|c|}
\hline \multicolumn{2}{|l|}{ Groups } & \multirow{2}{*}{$\begin{array}{l}\text { Group A } \\
(\mathrm{N}=10)\end{array}$} & \multirow{2}{*}{$\begin{array}{l}\text { Group B } \\
(\mathrm{N}=10)\end{array}$} & \multicolumn{2}{|c|}{ Chi-square Test } \\
\hline & & & & $\mathrm{X} 2$ & $\mathrm{p}$-value \\
\hline \multirow{2}{*}{ Blood loss } & No & $6(60 \%)$ & $6(60 \%)$ & \multirow{2}{*}{0.0} & \multirow{2}{*}{1.0} \\
\hline & present & $4(40 \%)$ & $4(40 \%)$ & & \\
\hline \multirow{2}{*}{ Continence } & NO & $0(0 \%)$ & $1(10 \%)$ & \multirow{2}{*}{1.05} & \multirow{2}{*}{0.3} \\
\hline & Present & $10(100 \%)$ & $9(90 \%)$ & & \\
\hline \multirow{2}{*}{ Frequent stooling } & No & $4(40 \%)$ & $4(40 \%)$ & \multirow{2}{*}{0} & \multirow{2}{*}{1.0} \\
\hline & Present & $6(60 \%)$ & $6(60 \%)$ & & \\
\hline \multirow{2}{*}{ Enterocolitis } & No & $8(80 \%)$ & $7(70 \%)$ & \multirow{2}{*}{0.4} & \multirow{2}{*}{0.2} \\
\hline & Present & $2(20 \%)$ & $3(30 \%)$ & & \\
\hline \multirow{2}{*}{ Constipation } & No & $7(70 \%)$ & $8(80 \%)$ & \multirow{2}{*}{0.3} & \multirow{2}{*}{0.6} \\
\hline & Present & $3(30 \%)$ & $2(20 \%)$ & & \\
\hline
\end{tabular}

\section{DISCUSSION}

Despite the obvious advancement of the management of Hirschsprung's disease, some patients suffer postoperatively even after apparently perfect pull-through. Some patients may still have disturbances of bowel function such as constipation and enterocolitis, therefore enormous ongoing researches are striving for improving HD outcomes either by applying new investigations including using of endoscopy for determining the diseased part accurately or by trying new treatment modalities such as implantation of neuronal stem cells in the bowel ${ }^{\left({ }^{11}\right)}$. One stage TEPT was both feasible and safe in the neonatal period, because mucosal dissection is much easier in neonatal age (less adherent mucosa and usually there is no repeated attacks of enterocolitis) ${ }^{(\mathbf{1 2})}$. The TERPT technique is preferable in straightforward cases, with a more distal localization of aganglionosis, and the Duhamel's technique is favourable when treating patients with long-segment disease 
affecting the proximal colon ${ }^{(13)}$. The most common early complications occurred during the first month following surgery; were anastomotic leakage, wound infection, hemorrhage and anastomotic stricture ${ }^{(14)}$. In this study the most common early complication after Modified Duhamel's was anastomotic leakage that was treated conservatively in 2 patients and required colostomy in one patient, and the most common early complication after TEPT was anastomotic stricture that responds well to anal bouginaging, one case required dilatation under general anesthesia.Rouzrokh and his colleagues recommended prophylactic anal bouginaging 2 weeks after the operation (15). Modified Duhamel's rates of postoperative fecal incontinence and operation time are nearly equal to TERPT procedure rates. Mao et al. found that the Duhamel's and TERPT interventions were similar in respect to rate of post-operative fecal continence and operation time ${ }^{(\mathbf{1 6})}$. Duhamel's procedure was associated with longer post-operative hospital stay and a lower rate of enterocolitis (11). Martins et al. evaluated fecal continence by anorectal manometry and profilometry, in patients operated for congenital megacolon, using either the modified Duhamel's technique or the transanal technique, and found that the two techniques were equivalent ${ }^{(17)}$. Arts et al. found that the experience of the main surgeon has a major effect on the long-term out-comes after HD operations ${ }^{(13)}$.

\section{Conclusion}

By comparing the two techniques (Modified Duhamel's and TEPT) for management of HD; we found that the two techniques were nearly equivalent in the post-operative outcomes. Currently, as there was no evidence suggesting that one technique had significant superiority over another, so it was up to surgeon's choice to select the technique that was easy and feasible in his hands, but TEPT was preferable for neonates, with no past history of enterocolitis, using modified Duhamel's if the two staplers were available is safe and with less complications.

\section{REFERENCES:}

1. Dasgupta $\mathbf{R}$ and Langer JC (2004): Hirschsprung disease. Curr. Probl .Surg., 41(12):942-988

2. Okamoto E and Ueda T (1967): Embryogenesis of intramural ganglia of the gut and its relation to Hirschsprung's disease. J. Pediatr. Surg., 2(5):437-443

3. Amiel J and Lyonnet S (2001): Hirschsprung disease, associated syndromes, and genetics: a review. J. Med. Genet., 38:729-739

4. Singh SJ, Croaker GD, Manglick $\mathbf{P}$ et al. (2003): Hirschsprung's disease: the Australian Paediatric Surveillance Unit's experience. Pediatr. Surg. Int ., 19(4):247-250

5. Smith G and Cass D (1991): Infantile Hirschsprung's disease is barium enema useful? Pediatr. Surg. Int., 6:318-321

6. Gunnarsdóttir A and Wester $\mathbf{T}$ (2011): Modern treatment of HirscHsprung's disease. Scandinavian Journal of Surgery, 100: 243-249

7. Swenson o and Bill AH (1948): Resection of rectum and rectosigmoid with preservation of the sphincter for benign spastic lesions producing megacolon. Surg., 24: 212-220

8. Rehbein $F$ and Von $Z$ (1960): Results with abdominal resection in Hirschsprung's disease. Arch Dis. Child., 35:29-37

9. So HB, Becker JM, Schwartz DL et al. (1998): Eighteen years experience with neonatal Hirschsprung's disease treated by endorectal pull-through without colostomy. J. Pediatr. Surg., 33(5):673-675

10. Roshni D and Jacob CL (2005): Transanal pull-through for Hirschsprung disease. Semin. Pediatr. Surg. , 14:64-71

11. Puri P, Tani G and O'Donnell A et al. (2017): Increased population of 
immature enteric glial cells in the resected proximal ganglionic bowel of Hirschsprung's disease patients, Journal of Surgical Research, 218:150155.

12. Hassan H (2009): One-stage transanal endorectal pull- through procedure for Hirschsprung's disease in neonates.In Annals of Pediatric Surgery, 5: 21-26.

13. Arts E, Botden S, Lacher $M$ et al. (2016): Duhamel versus transanal endorectal pull through (TERPT) for the surgical treatment of Hirschsprung's disease. Tech. Coloproctol., 20(10): 677-682

14. Izadi M, Mansour-Ghanaei F, Jafarshad $\mathbf{R}$ et al. (2009): Clinical manifestations of Hirschsprung's disease. Middle East Journal of Digestive Diseases, 1(2) :68-73.

15. Rouzrokh $\mathbf{M}$, khaleghnejad $\mathbf{A}$,
Mohejerzadeh L et al. (2010): What is the most common complication after one-stage transanal pull-through in infants with Hirschsprung's disease? Pediatric Surgery International, 26(10) :967-970

16. Mao YZ, Tang ST and Li S (2017): Duhamel operation vs. transanal endorectal pull-through procedure for Hirschsprung disease: A systematic review and meta-analysis. J. Pediatr. Surg., 16: 47-53.

17. Martins E, Peterlini F, Fagundes D et al. (2009): Clinical, manometric and profilometric evaluation after surgery for Hirschsprung's disease. Comparison between the modified Duhamel and the transanal rectosigmoidectomy techniques. Acta Cir. Brasil., 24(5): 416-422. 